\title{
Redesigning fruit and vegetable distribution network in Tehran using a city logistics model
}

\author{
Farshad Saeedia ${ }^{*}$, Ebrahim Teimoury ${ }^{\mathrm{a}}$ and Ahmad Makui ${ }^{\mathrm{a}}$
}

${ }^{a}$ Department of Industrial Engineering, Iran University of Science and Technology

\begin{tabular}{l}
\hline C H R O N I C L E \\
\hline Article history: \\
Received November 18, 2017 \\
Received in revised format: \\
April 28, 2018 \\
Accepted May 4, 2018 \\
Available online \\
May 5, 2018 \\
\hline Keywords: \\
City logistics \\
Carbon emission \\
Urban distribution centers \\
Fruit and vegetable distribution \\
network \\
Network design \\
Queuing theory
\end{tabular}

\begin{abstract}
A B S T R A C T
Tehran, as one of the most populated capital cities worldwide, is categorized in the group of highly polluted cities in terms of the geographical location as well as increased number of industries, vehicles, domestic fuel consumption, intra-city trips, increased manufacturing units, and in general excessive increase in the consumption of fossil energies. City logistics models can be effectively helpful for solving the complicated problems of this city. In the present study, a queuing theory-based bi-objective mathematical model is presented, which aims to optimize the environmental and economic costs in city logistics operations. It also tries to reduce the response time in the network. The first objective is associated with all beneficiaries and the second one is applicable for perishable and necessary goods. The proposed model makes decisions on urban distribution centers location problem. Subsequently, as a case study, the fruit and vegetable distribution network of Tehran city is investigated and redesigned via the proposed modelling. The results of the implementation of the model through traditional and augmented $\varepsilon$-constraint methods indicate the efficiency of the proposed model in redesigning the given network.
\end{abstract}

C 2018 by the authors; licensee Growing Science, Canada.

\section{Introduction}

Meeting citizens' public needs, especially foods is one of the most important and perhaps the most principal elements of urban services. Besides, providing welfare and comfort for citizens entails proper deployment, optimal distribution, comprehensiveness and perfectness of applications and usages, as well as diversity of supplied products in markets and shopping centers. This is because proper deployment of supply centers has a significant impact on reducing intra-city trips and traffic jams as well as energy- and cost- savings. It is impossible to accomplish proper deployment of supply centers without considering the geographical factors of population, location, and space as well as other factors such as transportation infrastructures, land, fair access, adaptability and adjacency, population density, capability and capacity, environmental considerations, and parking space. In this regard, it is essential to develop models that take into account and apply these factors in urban designs to the possible extent (Yang et al., 2016).

Based on the research conducted by the United Nation (UN), it is estimated that more than $60 \%$ of the entire world's population will be residing in urban areas by 2030 and above $70 \%$ by 2050 . High density of population in urban areas has caused various problems including high energy consumption rate, air pollution, and traffic congestion. Advancement of logistic systems, such as on-time and smart retailing,

* Corresponding author. Tel. : +989123950902

E-mail address: saeedifarshad1@gmail.com (F. Saeedi)

(C) 2019 by the authors; licensee Growing Science, Canada. doi: $10.5267 /$ j.dsl.2018.5.003 
inclines suppliers to keep their inventories at a low level and try to make savings in storage costs. These factors have resulted in the increased demand for commodities and services and simultaneously reduced volume of these demands, followed thereby by increased traffic of freight vehicles and, consequently, increased emission of pollutants (Taniguchi et al., 2001). City logistics models can be effective for solving such complicated problems (Taniguchi et al., 2014). In this regard, several policy measures have been implemented and assessed using various models in a number of cities around the world (Taniguchi et al., 2014).

In the present study, a three-level network is investigated in order to optimize the city logistics distribution operations and simultaneously to reduce the economic and environmental costs. Meanwhile, it is attempted to minimize the response time in the network. In the given network, the first level represents the logistic centers in suburban areas, the second level represents the distribution centers inside the city, and the third level represents the sales terminals as demand points across the city. It is supposed to select some fixed sites for constructing urban distribution centers. Besides, it is necessary to make decisions on the capacity of distribution centers as well as the manner of allocating these distribution centers to the logistic centers and the sales terminals to the distribution centers. The demand for commodities is considered as probabilistic and the network is modelled based on the queuing theory. For the provided model, the policy of putting tax on carbon and applying the lowcarbon emission resources for deployment at urban distribution centers is used. Afterwards, the mathematical model presented in this work is applied as a case study in order to design a fruit and vegetable distribution network in Tehran. Initially, the fruit distribution status in this city is described. Then, using the data and information gathered from the sources and organizations affiliated to Tehran Municipality, it is attempted to adjust the required parameters of the problem to the possible extent. Finally, the results derived from solving the mathematical model via traditional and augmented $\varepsilon$ constraint methods in this case study are presented. Results of the present study indicate high efficiency of the proposed model in achieving its objectives and the preference of the augmented approach in comparison with traditional one. At the end, the conclusion as well as some suggestions for future studies are provided.

\section{Review of literature}

City logistics was introduced for the first time by Taniguchi in 2001. Since then, many researchers have presented papers and studies with a focus on this area. Notwithstanding these works, mathematical modelling of city logistics requires further attempts as well as development of relevant models. In this regard, numerous terms and definitions have been proposed to date in order to express the concept of city logistics. Among them, it would be better to adopt the most comprehensive definition (Wolpert \& Reuter, 2012). Some of the definitions proposed in this regard are as follows:

a. Freight transportation in urban areas (Barceló et al., 2005)

b. Routing and displacing commodities and associated activities such as warehousing (Qiu \& Yang, 2005)

c. Optimizing urban freight transportation systems (Crainic et al., 2009)

d. Providing various services for the optimal management of displacement of commodities in cities (Dablanc, 2007)

e. Optimization process of logistics and transportation activities in urban areas considering all beneficiaries (Taniguchi et al., 2001)

The last definition for city logistics by Taniguchi et al. (2001) seems to be more comprehensive.

Objectives of city logistics can be defined from two perspectives. In the first perspective, these objectives can be categorized as economic, environmental, and social, while the second perspective deals with mobility, sustainability, viability, and flexibility (Taniguchi et al., 2014). 
So far, numerous studies have been conducted in order to investigate and identify the modellings of city logistics presented by various researchers (Anand et al., 2012; Taniguchi et al., 2014; Anand et al., 2015; Muñuzuri \& Pablo, 2012; Wolpert \& Reuter, 2012).

According to these studies, most of the modellings have been performed with a focus on the economic and environmental objectives and some others have addressed the problems of crisis and disaster as well as the issue of emergency logistics in cities (He et al., 2013). Optimizing the location of logistic facilities in metropolitan areas at any time, either crisis or normal conditions, is considered of great importance due to its considerable effect on traffic congestion and air pollution (Duren \& Miller, 2012).

The majority of the modellings have been performed from the viewpoint of city's authorities and managers. However, the sustainable and green objectives have been highly regarded by the authors in recent years (Teimoury et al., 2017). Among such research projects, Yang et al. (2016) and Moutaoukil et al. (2015) can be mentioned.

Several innovative projects have been aimed to reduce the emission of $\mathrm{CO}_{2}$ and greenhouse gases in urban areas, which has been accomplished mainly in three ways: stabilizing the flow of commodities, applying the low-emission vehicles, and setting the regulations of access control to urban centers. Stabilization of the flow of commodities, which is mainly based on the use of a single distribution center, seems to be a suitable solution for optimizing the final delivery inside the city (Taniguchi and Thompson, 2014).

In addition to these works, it would be an interesting idea to apply the queuing theory in order to optimize the demand responding time in city logistics systems and, consequently, focus on increasing the customer satisfaction in addition to attempting to reduce logistic costs (Saeedi et al., 2018).

\section{Problem presentation and mathematical modelling}

Freight vehicles gather commodities and goods from logistic centers (LC) in the suburban areas and, then, transfer them to the intra-city distribution centers (DC) in order for further processes (including packaging, storage, combining, barcoding, etc.). Eventually, these commodities are distributed extensively among sales terminals (ST), also called demand points (Saeedi et al., 2018). In the present study, objective of the problem was to select some fixed sites for constructing urban distribution centers. Due to the limitation of capital costs, only a few number of distribution centers could be constructed and, subsequently, only a certain number of these activated centers would receive the governmental support to be equipped with low-carbon facilities (e.g. employment of the equipment, which can consume natural liquid gas as fuel, or more complex structures in designing distribution centers with optimal carbon rate). Furthermore, regarding the carbon tax policies adopted by the government and city managers, the costs of carbon emissions resulted from processing of commodities in distribution centers as well as transportation operations by vehicles within the network should be taken into consideration. The ultimate objective was to minimize the total operational costs as well as to minimize the response time. The first objective could be attractive for all beneficiaries and the second one is appropriately applicable for perishable and necessary commodities.

In this network, the nodes and commodities played the roles of server and customer, respectively. At the network's nodes, operations such as production, storage, packaging, barcoding, cutting, mixing, combining, loading, discharging, sorting, processing, and delivery were performed. The governing conditions of the problem were associated with uncertainty. Thus, under such conditions, the demand for commodities and the service-providing time were considered as probabilistic. 


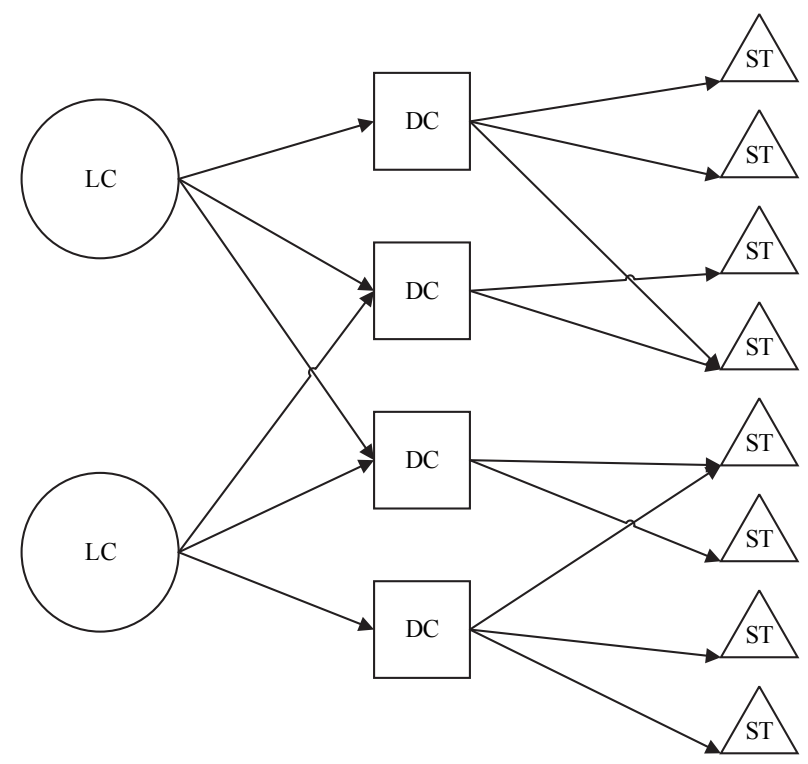

Fig. 1. City logistics distribution network (Teimoury et al., 2017)

\subsection{Assumptions}

- Each sales terminal can supply the demand for a certain commodity only from a single distribution center, but there is no limitation for supplying the sales terminals' demands from several distribution centers.

- Each node of the network is considered as an M/M/1 queuing system.

- Service time at the network's nodes is probabilistic and is considered as having an exponential distribution function.

- Entry of demand into sales terminals is considered probabilistic with an exponential distribution function and the value of demand is considered as having a uniform distribution function.

\subsection{Symbols and parameters}

I Index for LCs

$\mathrm{J} \quad$ Index for DCs to be set up in candidate sites

$\mathrm{K} \quad$ Index for STs

$\mathrm{R} \quad$ Index for commodity

TC Total operational cost in network

RT System's response time

$D_{k}^{r} \quad$ Demands of commodity type $\mathrm{r}$ for ST k

$\mathrm{d}_{\mathrm{ij}} \quad$ Distance from LC $\mathrm{i}$ to $\mathrm{DC} \mathrm{j}$

$\mathrm{d}_{\mathrm{jk}} \quad$ Distance from DC $\mathrm{j}$ to ST $\mathrm{k}$

$\mathrm{f}_{\mathrm{j}} \quad$ Unit construction cost for $\mathrm{DC} \mathrm{j}$

B Total fixed cost at DCs

$v_{j}^{r} \quad$ Cost unit of processing at distribution center $\boldsymbol{j}$ for r-type commodity

$t_{j}^{r} \quad$ Cost unit of transport of $r$-type commodity from distribution center $\boldsymbol{j}$ to each sales terminal

$s_{i}^{r} \quad$ Cost unit of transport of r-type commodity from logistics center $\boldsymbol{i}$ to each distribution center

$\mathrm{pe}_{\mathrm{j}} \quad$ Carbon emission unit from all processing stages at distribution center $\boldsymbol{j}$

te $_{j} \quad$ Carbon emission unit of vehicles from distribution center $\boldsymbol{j}$ to each sales terminal 
$\mathrm{e}_{\mathrm{i}} \quad$ Carbon emission unit of vehicles from logistic center $\boldsymbol{i}$ to each distribution center

$\mathrm{U}_{\mathrm{i}} \quad$ Commodity supply capacity of logistics center $\boldsymbol{i}$

W Number of DCs planned to construct

$\mathrm{V}$ Number of resources with low carbon emissions that should be allocated to the distribution centers

a Carbon tax rate

b Carbon emission reduction percentage at each distribution center where the lowcarbon resources have been considered

$\lambda \quad$ Demand entry rate at network's nodes $\left(\lambda_{i}, \lambda_{j}\right.$ and $\left.\lambda_{k}\right)$

$\mu \quad$ Service-providing rate at network's nodes $\left(\mu_{i}, \mu_{j}\right.$ and $\left.\mu_{k}\right)$

$\delta \quad$ Parameter of negative exponential distribution

c Lower bound of a uniformly distributed random variable that indicates the quantity of commodity in a demand

d Upper bound of a uniformly distributed random variable that indicates the quantity of commodity in a demand

$t_{i j k}^{r} \quad$ Response time of the system for commodity type $\mathrm{r}$ from node $\mathrm{i}$ to node $\mathrm{k}$, going through DC located at node $\mathrm{j}$

$W T_{s y s}^{r} \quad$ Sojourn time of commodity type $\mathrm{r}$ in the system

$W T_{q}^{r} \quad$ Waiting time of commodity type $\mathrm{r}$ in the queue

$L R_{\text {sys }} \quad$ Average number of commodities in the system

$L R_{q} \quad$ Average number commodities in the queue

$T R_{i j}^{r} \quad$ Transportation time for commodity type $\mathrm{r}$ from node $\mathrm{i}$ to node $\mathrm{j}$

$T R_{j k}^{r} \quad$ Transportation time for commodity type $\mathrm{r}$ from node $\mathrm{j}$ to node $\mathrm{k}$

$v_{i j}^{r} \quad$ Transportation speed for commodity type $\mathrm{r}$ from node $\mathrm{i}$ to node $\mathrm{j}$

$v_{j k}^{r} \quad$ Transportation speed for commodity type $\mathrm{r}$ from node $\mathrm{j}$ to node $\mathrm{k}$

\subsection{Decision variables}

$x_{\mathrm{ij}}^{r} \quad$ Amount of r-type commodity that is carried from logistics center $\boldsymbol{i}$ to distribution center $\boldsymbol{j}$

$Z_{j} \quad 1$ if DC $j$ is set up; 0 , otherwise

$\mathrm{C}_{\mathrm{j}} \quad$ Processing capacity designed at distribution center $\boldsymbol{j}$

$\mathrm{P}_{\mathrm{j}} \quad$ Equal to 1 if low-carbon resources are allocated to distribution center $\boldsymbol{j} ; 0$ otherwise

$y_{i j}^{r} \quad 1$ if commodity type $\mathrm{r}$ is delivered from LC $\mathrm{i}$ to $\mathrm{DC} \mathrm{j} ; 0$, otherwise

$y_{j k}^{r} \quad 1$ if commodity type $\mathrm{r}$ is delivered from DC $\mathrm{j}$ to ST $\mathrm{k} ; 0$, otherwise

\subsection{Mathematical model}

$$
\begin{aligned}
& \operatorname{Min} T C=\left[\sum_{j} f_{j} C_{j} Z_{j}\right.\left.+\sum_{j} \sum_{k} \sum_{r} v_{j}^{r} E\left(D_{k}^{r}\right) y_{j k}^{r}+\sum_{j} \sum_{k} \sum_{r} t_{j}^{r} E\left(D_{k}^{r}\right) d_{j k} y_{j k}^{r}+\sum_{i} \sum_{j} \sum_{r} s_{i}^{r} x_{i j}^{r} d_{i j}\right] \\
&+a\left[\sum_{j}\left(1-b P_{j}\right) p e_{j} \sum_{k} \sum_{r} E\left(D_{k}^{r}\right) y_{j k}^{r}+\sum_{j} \sum_{k} \sum_{r} t e_{j} E\left(D_{k}^{r}\right) d_{j k} y_{j k}^{r}+\sum_{i} \sum_{j} \sum_{r} e_{i} x_{i j}^{r} d_{i j}\right]
\end{aligned}
$$

$\operatorname{Min} R T=\sum_{i} \sum_{j} \sum_{k} \sum_{r} t_{i j k}^{r}$ 


$$
\begin{aligned}
& y_{i j}^{r} \leq Z_{j} \quad \forall i \in I, j \in J, r \in R \\
& y_{j k}^{r} \leq Z_{j} \quad \forall j \in J, k \in K, r \in R \\
& x_{\mathrm{ij}}^{r} \leq \text { M. } y_{i j}^{r} \quad \forall i \in I, j \in J, r \in R \\
& P_{j} \leq Z_{j} \quad \forall j \in J \\
& C_{j} \leq M . Z_{j} \quad \forall j \in J \\
& C_{j} \geq \sum_{k} \sum_{r} E\left(D_{k}^{r}\right) y_{j k}^{r} \quad \forall j \in J \\
& \sum_{j} C_{j} \geq \sum_{k} \sum_{r} E\left(D_{k}^{r}\right) \\
& C_{j} \geq \sum_{i} \sum_{r} x_{\mathrm{ij}}^{r} \quad \forall j \in J \\
& \sum_{j} C_{j} \geq \sum_{i} \sum_{j} \sum_{r} x_{\mathrm{ij}}^{r} \\
& \sum_{j} \sum_{r} x_{\mathrm{ij}}^{r} \leq U_{i} \\
& \sum_{i} \sum_{j} \sum_{r} x_{\mathrm{ij}}^{r} \leq \sum_{i} U_{i} \\
& \sum_{j} E\left(D_{k}^{r}\right) y_{j k}^{r} \geq E\left(D_{k}^{r}\right) \quad \forall k \in K, r \in R \\
& \sum_{i} x_{\mathrm{ij}}^{r} \geq \sum_{k} E\left(D_{k}^{r}\right) y_{j k}^{r} \quad \forall j \in J, r \in R \\
& \begin{array}{ll}
\sum_{i} \sum_{r} x_{\mathrm{ij}}^{r} \geq \sum_{k} \sum_{r} E\left(D_{k}^{r}\right) y_{j k}^{r} & \forall j \in J \\
\sum_{i} \sum_{j} x_{\mathrm{ij}}^{r} \geq \sum_{j} \sum_{k} E\left(D_{k}^{r}\right) y_{j k}^{r} & \forall r \in R
\end{array} \\
& \sum_{i} \sum_{j} \sum_{r} x_{\mathrm{ij}}^{r} \geq \sum_{k} \sum_{r} E\left(D_{k}^{r}\right) \\
& \sum_{j \in J} f_{j} z_{j} \leq B \quad \forall i, j, r \\
& \sum Z_{j} \leq W \\
& \sum_{j}^{j} P_{j} \leq V \\
& \sum_{j} \sum_{r} y_{i j}^{r} \geq 1 \quad \forall i \in I \\
& \sum_{k} \sum_{r} y_{j k}^{r} \geq z_{j} \quad \forall j \in J \\
& \begin{array}{ll}
\sum_{i} y_{i j}^{r}=z_{j} & \forall j \in J, r \in R \\
\sum_{j} y_{j k}^{r}=1 & \forall k \in K, r \in R
\end{array} \\
& t_{i j k}^{r}=W T_{i}^{r}+W T_{j}^{r}+W T_{k}^{r}+T R_{i j}^{r}+T R_{j k}^{r} \\
& Z_{j}, P_{j} y_{i j}^{r}, y_{j k}^{r}=0,1 \quad \forall i \in I, j \in J, k \in K, r \in R
\end{aligned}
$$




$$
\begin{array}{ll}
x_{\mathrm{ij}}^{r} \geq 0 \cap x_{\mathrm{ij}}^{r} \in Z & \forall i \in I, j \in J, r \in R \\
C_{j} \geq 0 \cap C_{j} \in Z & \forall j \in J
\end{array}
$$

The first objective function minimizes the total operational cost. The total operational cost is comprised of two parts, the first of which is the total operation cost regardless of the carbon tax cost, and the second is the carbon tax cost imposed on carbon due to implementation of the carbon tax policy. The first part includes four items: fixed cost of constructing the distribution center, total variable cost of processing at the distribution center, total cost of delivery from distribution centers to sales terminals, and total cost of transportation from logistics centers to distribution centers. On the other hand, the second part consists of three items: the carbon cost resulting from the processing stages at distribution center, cost of delivery from distribution center to sales terminal, and cost of transportation from logistics center to distribution center. Moreover, the second objective function minimizes the total response time in the network as well.

Constraints (3) and (4) state that a distribution center cannot join the distribution activities as long as it is not constructed. Constraint (5) states that some amount of a certain commodity will be delivered from a certain logistics center to a certain distribution center only when the relationship between that logistics and distribution center has been established. Constraint (6) states that only the activated distribution centers will be equipped with low-carbon resources and equipment. Constraint (7) states that only the activated distribution centers will have capacity. Constraint (8) expresses that the capacity of each distribution center should be larger than or equal to its total output flow. Constraint (9) states that the sum of capacities of all distribution centers should be larger than or equal to the sum of demands of the sales terminals. Constraint (10) states that the capacity of each distribution center should be larger than or equal to its total input flow. Constraint (11) states that the sum of capacities of all distribution centers should be larger than or equal to the total flow that is transferred from all logistics centers to all distribution centers, which means that the distribution centers should be large enough for storing all the commodities carried from logistics centers. Constraints (12) and (13) refer to the logistics center's ability to supply commodities. Constraint (12) indicates that the total amount of the commodity that is transferred from each logistics center to the distribution centers should be less than the capacity of that logistics center. Constraint (13) also shows that the total amount of the commodity that is transferred from logistics centers to distribution centers should be less than total capacity of the logistics centers. Constraint (14) states that the sum of flows of the r-type commodity entering from all distribution centers into each sales terminal should meet the demand for the r-type commodity of that sales terminal. Constraint (15) shows that for each commodity, the input flow to each distribution center should be larger than or equal to its output flow. Constraint (16) states that the total input flow to a distribution center should be larger than or equal to its total output flow. Constraint (17) states that for each commodity, sum of the output flows coming out of all logistics centers should be larger than or equal to the sum of demands of all distribution centers. Constraint (18) shows that the total output flow coming out of the logistics centers should meet the total demand of the sales terminals. Constraint (19) states that the sum of fixed costs of the activated distribution centers should not be larger than the value of the available budget. Constraint (20) shows that W distribution centers should be constructed. Constraint (21) states that the resources with low carbon emission should be allocated only to V activated distribution centers. Constraint (22) ensures that all logistics centers will join the distribution activities. Constraint (23) states that none of the activated distribution centers should be without relationship. In fact, the purpose of considering Constraints (22) and (23) is to utilize the potential of all logistical centers and activated distribution centers for supplying the commodities. In cases that the capacity of the intended centers is at such a level that may seem very difficult even to supply demands of the sales terminals in unit of time, there will be no need for considering these two constraints, and the model itself will attempt to utilize the capacity of all these centers in order to supply the given demand. Constraint (24) shows that each distribution center can obtain its demand for r-type commodity 
from a single logistics center at most. Similarly, Constraint (25) shows that each sales terminal can obtain its demand for r-type commodity from at most a single distribution center. Constraint (26) shows that the system's response time for r-type commodity, which is carried from the logistics center $\boldsymbol{i}$ to the sales terminal $\boldsymbol{k}$ through the distribution center $\boldsymbol{j}$, is equal to that commodity's duration of presence at the first to third levels of the network plus the transportation time of that commodity between the network's levels. It should be noted that the total time of presence in the system $\left(W T_{s y s}\right)$ is equal to the sum of the times of presence at the first to third levels of the network. Constraint (27) states that variables $Z_{j}, P_{j}, y_{i j}^{r}$, and $y_{j k}^{r}$ can take the values of 0 and 1 . Constraint (28) and (29) also express that variables $x_{\mathrm{ij}}^{r}$ and $C_{j}$ have non-negative and integer values.

\subsection{Queuing model}

The studied queuing network is a series-parallel network consisted of three levels. At each serviceproviding node in the network, the queuing system is assumed as $\mathrm{M} / \mathrm{M} / 1$ and service-providing is performed with an exponential distribution with $\boldsymbol{\mu}$ parameter. Besides, the system is based on the FIFO (first-in/first-out) approach. It is assumed that the demand for commodities at demand point $\boldsymbol{k}$ follows an exponential distribution with parameter $\lambda_{k}$. Since each distribution center provides services for a group of the demand points, the demand of each of these distribution centers $\left(\lambda_{j}\right)$ would be equal to the total demand of its relevant downstream service-receivers. Therefore, it follows the following equation:

$$
\lambda_{j}=\sum_{k} \lambda_{k} y_{j k} \quad \forall j \in J
$$

Moreover, commodity demand for logistics centers follows the exponential distribution, the parameter of which can be obtained through the following equation:

$$
\lambda_{i}=\sum_{j} \lambda_{j} y_{i j}=\sum_{j} \sum_{k} \lambda_{k} y_{i j} y_{j k} \quad \forall i \in I
$$

Therefore, the schematic figure of the network would be as follows:

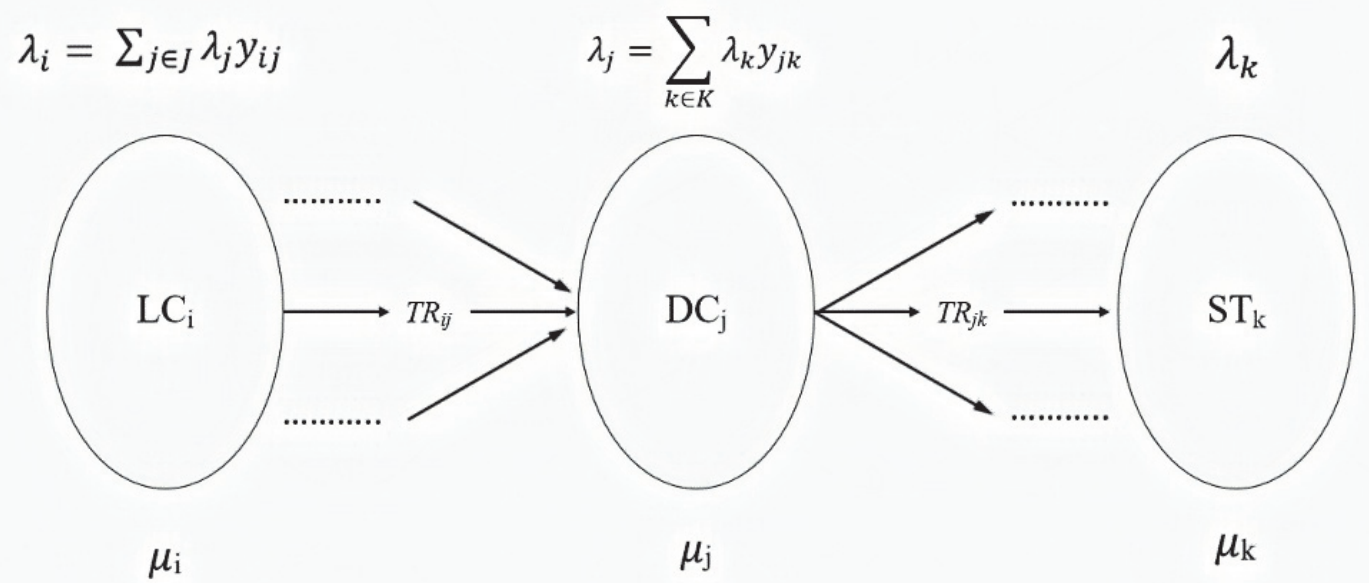

Fig. 2. Queuing system of city logistics distribution network

In this model, the demand for a commodity is expressed by two indices of demand occurrence and demand size at each time of occurrence. It is assumed that occurrence of the demand for each commodity is a random variable $U$ with exponential distribution and density function $f_{u}(u)$, and the demand size at each time of occurrence is a random variable $V$ with uniform distribution and density function $f_{v}(v)$.

Since these two random variables were independent from each other, the following equations hold: 


$$
\begin{aligned}
& f_{U}(u)=\left\{\begin{aligned}
\delta e^{-\delta u}, & u \geq 0 \\
0, & u<0
\end{aligned}\right. \\
& f_{V}(v)=\left\{\begin{aligned}
\frac{1}{d-c}, & c<v<d \\
0, & \text { otherwise }
\end{aligned}\right. \\
& E(D)=E(U V)=E(U) E(V)=\frac{c+d}{2 \delta}
\end{aligned}
$$

Therefore, in the multi-commodity model of the present study, we have:

$$
E\left(D_{k}^{r}\right)=\frac{c_{k}^{r}+d_{k}^{r}}{2 \delta_{k}^{r}}
$$

The r-type commodity demand of the sales terminals (demand points) follows the exponential distribution with parameter $\lambda_{k}^{r}$. Also, $\rho$ is the productivity rate and the following equations hold:

$$
\begin{aligned}
& \lambda_{k}^{r}=\frac{1}{E\left(D_{k}^{r}\right)}=\frac{2 \delta_{k}^{r}}{c_{k}^{r}+d_{k}^{r}} \\
& \rho=\frac{\lambda_{k}^{r}}{\mu_{k}}=\frac{1}{\mu_{k} E\left(D_{k}^{r}\right)}=\frac{2 \delta_{k}^{r}}{\mu_{k}\left(c_{k}^{r}+d_{k}^{r}\right)}
\end{aligned}
$$

According to the queuing theory, indices of the $\mathrm{M} / \mathrm{M} / 1$ queuing model are as follows (Teimoury et al., 2017):

$$
\begin{aligned}
& f_{w t}(t)=(\mu-\lambda) e^{-(\mu-\lambda) t} \\
& F_{W T}(t)=P(W T \leq t)=\int_{0}^{t}(\mu-\lambda) e^{-(\mu-\lambda) t} d t=1-e^{-(\mu-\lambda) t} \\
& W T=E(W T)=\int_{0}^{\infty} f_{w t}(t) t d t=\int_{0}^{\infty}(\mu-\lambda) e^{-(\mu-\lambda) t} t d t=\frac{1}{\mu-\lambda} \\
& W T_{q}=W T-\frac{1}{\mu}=\frac{\lambda}{\mu(\mu-\lambda)} \\
& L R=\lambda W T=\frac{\lambda}{\mu-\lambda} \\
& L R_{q}=\lambda W T_{q}=\frac{\lambda^{2}}{\mu(\mu-\lambda)}
\end{aligned}
$$

According to the above-mentioned discussions and equations, with regard to our discussion on the queuing model of the given problem in the present study, Eq. (44) shows the average duration of stay in the system in three stages of the network. Eqs. (45-47) show the average duration of waiting in the queue, average number of commodities existing in the system, and average number of commodities waiting in the queue, respectively.

$$
\begin{gathered}
W T_{s y s}=\sum_{r} \sum_{i} W T_{I}^{R}+\sum_{r} \sum_{j} W T_{J}^{R}+\sum_{r} \sum_{k} W T_{K}^{R}=\sum_{r} \sum_{i} \frac{1}{\mu_{i}-\lambda_{i}}+\sum_{r} \sum_{j} \frac{1}{\mu_{j}-\lambda_{j}}+\sum_{r} \sum_{k} \frac{1}{\mu_{k}-\lambda_{k}} \\
=\sum_{r} \sum_{i} \frac{1}{\mu_{i}-\sum_{j} \sum_{k} \frac{2 \delta_{k}^{r}}{c_{k}^{r}+d_{k}^{r}} y_{i j}^{r} y_{j k}^{r}}+\sum_{r} \sum_{j} \frac{1}{\mu_{j}-\sum_{k} \frac{2 \delta_{k}^{r}}{c_{k}^{r}+d_{k}^{r}} y_{j k}^{r}}+\sum_{r} \sum_{k} \frac{1}{\mu_{k}-\frac{2 \delta_{k}^{r}}{c_{k}^{r}+d_{k}^{r}}} \\
W T_{q}=\sum_{r} \sum_{i} \frac{\lambda_{i}}{\mu_{i}\left(\mu_{i}-\lambda_{i}\right)}+\sum_{r} \sum_{j} \frac{\lambda_{j}}{\mu_{j}\left(\mu_{j}-\lambda_{j}\right)}+\sum_{r} \sum_{k} \frac{\lambda_{k}}{\mu_{k}\left(\mu_{k}-\lambda_{k}\right)} \\
=\sum_{r} \sum_{i} \frac{\sum_{j} \sum_{k} \frac{2 \delta_{k}^{r}}{c_{k}^{r}+d_{k}^{r}} y_{i j} y_{j k}^{r}}{\mu_{i}\left(\mu_{i}-\sum_{j} \sum_{k} \frac{2 \delta_{k}^{r}}{c_{k}^{r}+d_{k}^{r}} y_{i j}^{r} y_{j k}^{r}\right)}+\sum_{r} \sum_{j} \frac{2 \sum_{k} \frac{2 \delta_{k}^{r}}{c_{k}^{r}+d_{k}^{r}} y_{j k}^{r}\left(\mu_{j}-\sum_{k} \frac{2 \delta_{k}^{r}}{c_{k}^{r}+d_{k}^{r}} y_{j k}^{r}\right)}{\left.\mu_{j}\right)} \sum_{r} \sum_{k} \frac{\frac{2 \delta_{k}^{r}}{c_{k}^{r}+d_{k}^{r}}}{\mu_{k}\left(\mu_{k}-\frac{2 \delta_{k}^{r}}{c_{k}^{r}+d_{k}^{r}}\right)}
\end{gathered}
$$




$$
\begin{aligned}
& L R_{s y s}=\sum_{r} \sum_{i} \frac{\lambda_{i}}{\left(\mu_{i}-\lambda_{i}\right)}+\sum_{r} \sum_{j} \frac{\lambda_{j}}{\left(\mu_{j}-\lambda_{j}\right)}+\sum_{r} \sum_{k} \frac{\lambda_{k}}{\left(\mu_{k}-\lambda_{k}\right)} \\
& =\sum_{r} \sum_{i} \frac{\sum_{j} \sum_{k} \frac{2 \delta_{k}^{r}}{c_{k}^{r}+d_{k}^{r}} y_{i j} y_{j k}^{r}}{\left(\mu_{i}-\sum_{j} \sum_{k} \frac{2 \delta_{k}^{r}}{c_{k}^{r}+d_{k}^{r}} y_{i j}^{r} y_{j k}^{r}\right)}+\sum_{r} \sum_{j} \frac{\sum_{k} \frac{2 \delta_{k}^{r}}{c_{k}^{r}+d_{k}^{r}} y_{j k}^{r}}{\left(\mu_{j}-\sum_{k} \frac{2 \delta_{k}^{r}}{c_{k}^{r}+d_{k}^{r}} y_{j k}^{r}\right)}+\sum_{r} \sum_{k} \frac{\frac{2 \delta_{k}^{r}}{c_{k}^{r}+d_{k}^{r}}}{\left(\mu_{k}-\frac{2 \delta_{k}^{r}}{c_{k}^{r}+d_{k}^{r}}\right)} \\
& L R_{q}=\sum_{r} \sum_{i} \frac{\lambda_{i}^{2}}{\mu_{i}\left(\mu_{i}-\lambda_{i}\right)}+\sum_{r} \sum_{j} \frac{\lambda_{j}^{2}}{\mu_{j}\left(\mu_{j}-\lambda_{j}\right)}+\sum_{r} \sum_{k} \frac{\lambda_{k}{ }^{2}}{\mu_{k}\left(\mu_{k}-\lambda_{k}\right)} \\
& =\sum_{r} \sum_{i} \frac{\left(\sum_{j} \sum_{k} \frac{2 \delta_{k}^{r}}{c_{k}^{r}+d_{k}^{r}} y_{i j} y_{j k}^{r}\right)^{2}}{\mu_{i}\left(\mu_{i}-\sum_{j} \sum_{k} \frac{2 \delta_{k}^{r}}{c_{k}^{r}+d_{k}^{r}} y_{i j}^{r} y_{j k}^{r}\right)}+\sum_{r} \sum_{j} \frac{\left(\sum_{k} \frac{2 \delta_{k}^{r}}{c_{k}^{r}+d_{k}^{r}} y_{j k}^{r}\right)^{2}}{\mu_{j}\left(\mu_{j}-\sum_{k} \frac{2 \delta_{k}^{r}}{c_{k}^{r}+d_{k}^{r}} y_{j k}^{r}\right)}+\sum_{r} \sum_{k} \frac{\left(\frac{2 \delta_{k}^{r}}{c_{k}^{r}+d_{k}^{r}}\right)^{2}}{\mu_{k}\left(\mu_{k}-\frac{2 \delta_{k}^{r}}{c_{k}^{r}+d_{k}^{r}}\right)}
\end{aligned}
$$

Based on the above points, the second objective function of the problem (Eq.2), which is equal to the total response time, is generally built up of aggregation of five parts:

$$
\min R T=W T_{s y s}+\sum_{r} \sum_{i} \sum_{j} T R_{i j}^{r} y_{i j}^{r}+\sum_{r} \sum_{j} \sum_{k} T R_{j k}^{r} y_{j k}^{r}
$$

By substituting, the following function is obtained:

$$
\begin{aligned}
\min R T=\sum_{r} \sum_{i} & \frac{1}{\mu_{i}-\sum_{j} \sum_{k} \frac{2 \delta_{k}^{r}}{c_{k}^{r}+d_{k}^{r}} y_{i j}^{r} y_{j k}^{r}}+\sum_{r} \sum_{j} \frac{1}{\mu_{j}-\sum_{k} \frac{2 \delta_{k}^{r}}{c_{k}^{r}+d_{k}^{r}} y_{j k}^{r}}+\sum_{r} \sum_{k} \frac{1}{\mu_{k}-\frac{2 \delta_{k}^{r}}{c_{k}^{r}+d_{k}^{r}}} \\
& +\sum_{r} \sum_{i} \sum_{j} T R_{i j}^{r} y_{i j}^{r}+\sum_{r} \sum_{j} \sum_{k} T R_{j k}^{r} y_{j k}^{r}
\end{aligned}
$$

\subsection{Linearization of the first objective function}

In the above model, item (1) in both the first and the second parts of the first objective function include the multiplication of two decision variables. To simplify the solution, it can be linearized using the following method.

For the first item in the first part, the following logical method can be used:

$$
A C_{j}= \begin{cases}C_{j} & \text { if } Z_{j}=1 \\ 0 & \text { if } Z_{j}=0\end{cases}
$$

By this definition, the previous multiplication of variables $C_{j}$ and $Z_{j}$ are converted into a single variable $A C_{j}$. The $A C_{j}$ equations based on $Z_{j}$ are represented in constraints of the model. However, regarding constraint (7), variable $Z_{j}$ can be entirely removed from the objective function without defining a variable such as $A C_{j}$.

For item (1) in the second part, the optimal solution can be obtained under the following conditions:

$$
C_{j}=\sum_{j} \sum_{k} \sum_{r} E\left(D_{k}^{r}\right) y_{j k}^{r}
$$

Therefore, here, $C_{j}$ is replaced for $\sum_{j} \sum_{k} \sum_{r} E\left(D_{k}^{r}\right) y_{j k}^{r}$. A non-negative interval variable $\boldsymbol{M C}$ is created, which can be specified as following:

$$
M C_{j}= \begin{cases}(1-b) p e_{j} \cdot C_{j} & \text { if } P_{j}=1 \\ p e_{j} \cdot C_{j} & \text { if } P_{j}=0\end{cases}
$$


Similarly, the $P_{j}$-based logical equations $M C_{j}$ are shown in the model's set of constraints.

Now, the first objective function of the problem can be specified as follows:

$$
\begin{aligned}
& \operatorname{Min} T C=\left[\sum_{j} f_{j} A C_{j}+\sum_{j} \sum_{k} \sum_{r} v_{j}^{r} E\left(D_{k}^{r}\right) y_{j k}^{r}+\sum_{j} \sum_{k} \sum_{r} t_{j}^{r} E\left(D_{k}^{r}\right) d_{j k} y_{j k}^{r}+\sum_{i} \sum_{j} \sum_{r} s_{i}^{r} x_{i j}^{r} d_{i j}\right] \\
& +a\left[\sum_{j} M C_{j}+\sum_{j} \sum_{k} \sum_{r} t e_{j} E\left(D_{k}^{r}\right) d_{j k} y_{j k}^{r}+\sum_{i} \sum_{j} \sum_{r} e_{i} x_{i j}^{r} d_{i j}\right]
\end{aligned}
$$

\section{Case study}

\subsection{Fruit distribution network in Tehran}

Tehran, as one of the most populated capital cities in the world, is also one of the highly polluted cities worldwide due to its increased population, industries, number of vehicles, and excessive increase in the consumption of fossil energies. Air pollution is among the most important environmental issues challenging the people living in this city. A considerable portion of the air pollution in cities is created by motor vehicles and moving resources.

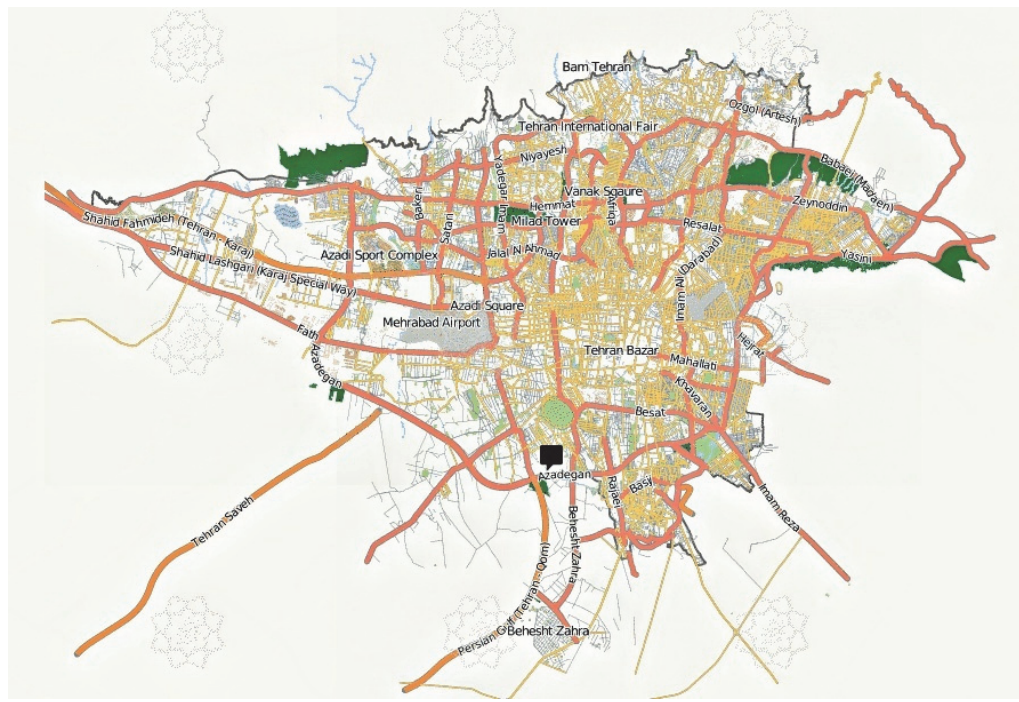

Fig. 3. Location of Tehran Central Market of Fruit and Vegetable

Several years ago, the Municipality constructed some markets and centers in order to eliminate the role of dealers, which consequently led to the emergence of the "Tehran Municipality Management of Fruit and Vegetable Organization". The purpose of this organization has been to establish the required facilities for providing and distributing the fruits and vegetables as well as agricultural crops. Since then, other duties and responsibilities have been also gradually delegated to the organization, some of which include constructing the Central Market of Fruit and Vegetable in order to provide the required facilities for fruit and vegetable transactions, supplying the daily markets, reducing the traffic load and thereby air pollution, gaining the control of distribution, and cutting off the exclusivity and eliminating dealers from market. In addition, the qualitative and quantitative development of the local markets in alignment with policies of fighting against overcharging was included in Tehran Municipality's programs. Accordingly, there are currently about 219 markets, local markets, and fruit and vegetable markets across Tehran, which in some way constitute Iran's largest foods and agricultural products supply network with the capacity of meeting the requirements of hundreds of thousands of people every day. The Central Market of Fruit and Vegetable of Tehran with an area of 270 ha, which is a logistic center, plays a significant role in managing the supply of demands for food in these markets, and is located in the southern part of the city. 
Referral of hundreds of thousands of people to these markets every day represents the considerable number of city trips made for meeting the daily needs of citizens. According to the results of the surveys conducted by Tehran Municipality's General Office of Social and Cultural Studies, the number of citizens who walk to these markets has been considerably increased in recent years. Besides, according to the same reports, the statistics indicates the reduced number of trips by personal cars for going to these markets. On the other hand, whole shopping of daily needs from markets along with improved accessibility of the markets has led to the reduced time and distance covered by those who use personal cars. Hence, by constructing and expanding the fruit and vegetable markets across city of Tehran, volume of intra-city trips by personal cars has been reduced considerably, which in turn has led to a considerable reduction in traffic congestion and air pollution as well as fuel consumption. This will be more perceivable when we see that Tehran has been facing the growth of population as well as annual increase of several thousands in the number of vehicles. Fig. 4 demonstrates the situation of the markets of fruit and vegetable across Tehran.

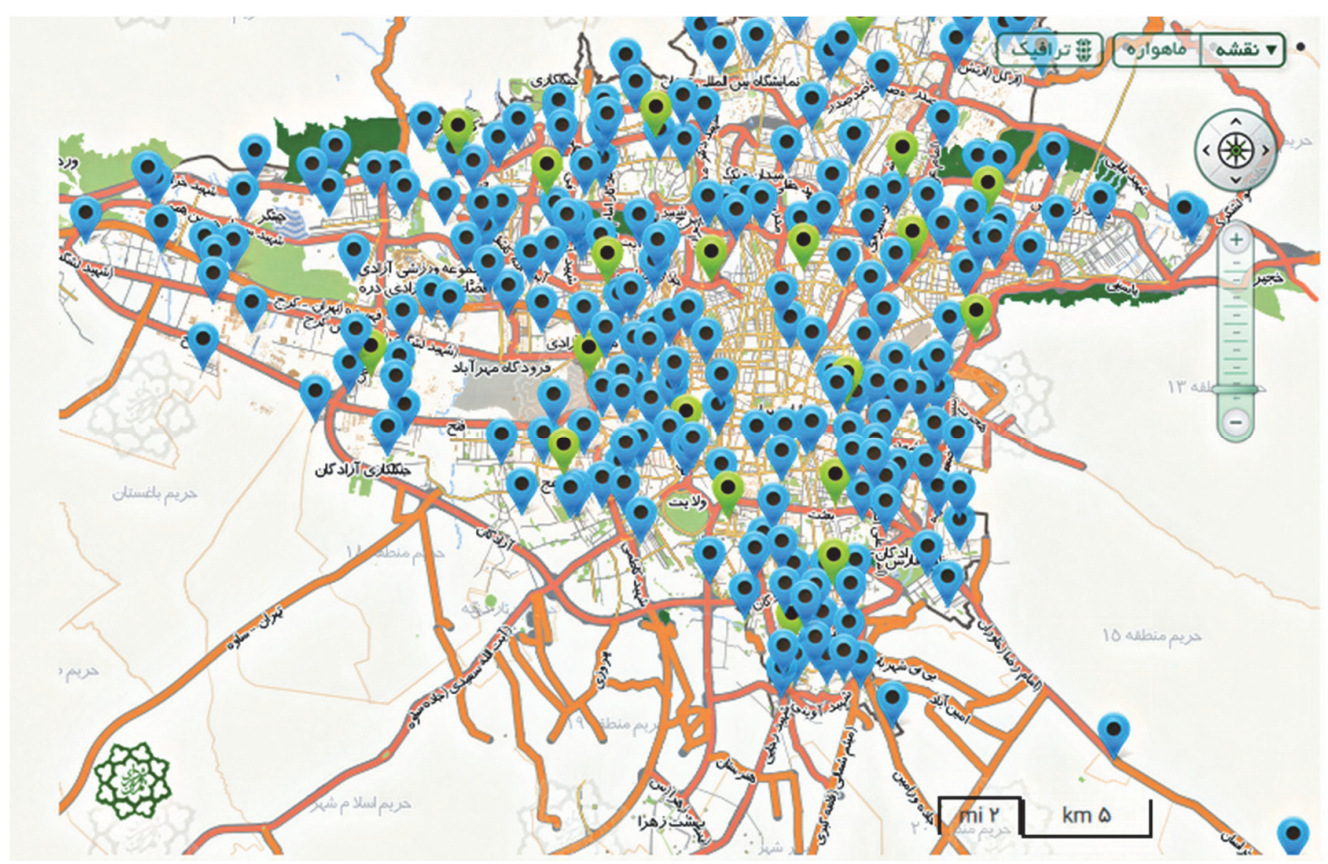

Fig. 4. Location of markets of fruit and vegetable in Tehran

\subsection{Necessity of redesigning fruit distribution network in Tehran}

Regarding the above-mentioned points, creation and development of fruit and vegetable markets across Tehran and constructing the central market of fruit and vegetable as a large logistic center seem to be successful in achieving the intended objectives of the relevant authorities and decision-makers to a large extent. Easy and fair access to the food and agricultural products, elimination of dealers and exclusivists, control and management of distribution of products, as well as reduction of the intra-city traffic load and air pollution are among the successfully accomplished objectives. However, in order to achieve these objectives more desirably, reduce the freight vehicles traffic load that has been so far disregarded in distribution operations, and reduce the pollutants resulted from operations of the freight vehicles in Tehran, the fruit and vegetable distribution network in Tehran requires to be redesigned. Transportation by freight vehicles among more than 200 markets and the central market, as the main supplier, entails long distances and, as a result, considerable environmental and economic costs. Therefore, such costs can be reduced by creating another level in the fruit distribution network in Tehran and constructing the intra-city distribution centers. The mathematical model presented in this study can be used as a useful pattern and tool in redesigning the fruit distribution network in Tehran. 


\subsection{Data and values of parameters}

The next stage is aimed to redesign the fruit and vegetable distribution network in Tehran by applying the proposed model and using the existing available information. In this study, the 22 districts of city of Tehran have been considered as the candidate points for constructing the urban distribution centers. Also, the information of 171 major sales markets, though the total number of these markets mounted to 219 as mentioned earlier, has been extracted by referring to the relevant organization. Furthermore, the direct distances among the centers of these 22 districts and the Tehran Fruit and Vegetable Central Market as well as the distances of the centers of these districts from the sales markets were calculated and gathered in kilometer. Fig. 5 demonstrates the 22 districts of Tehran.

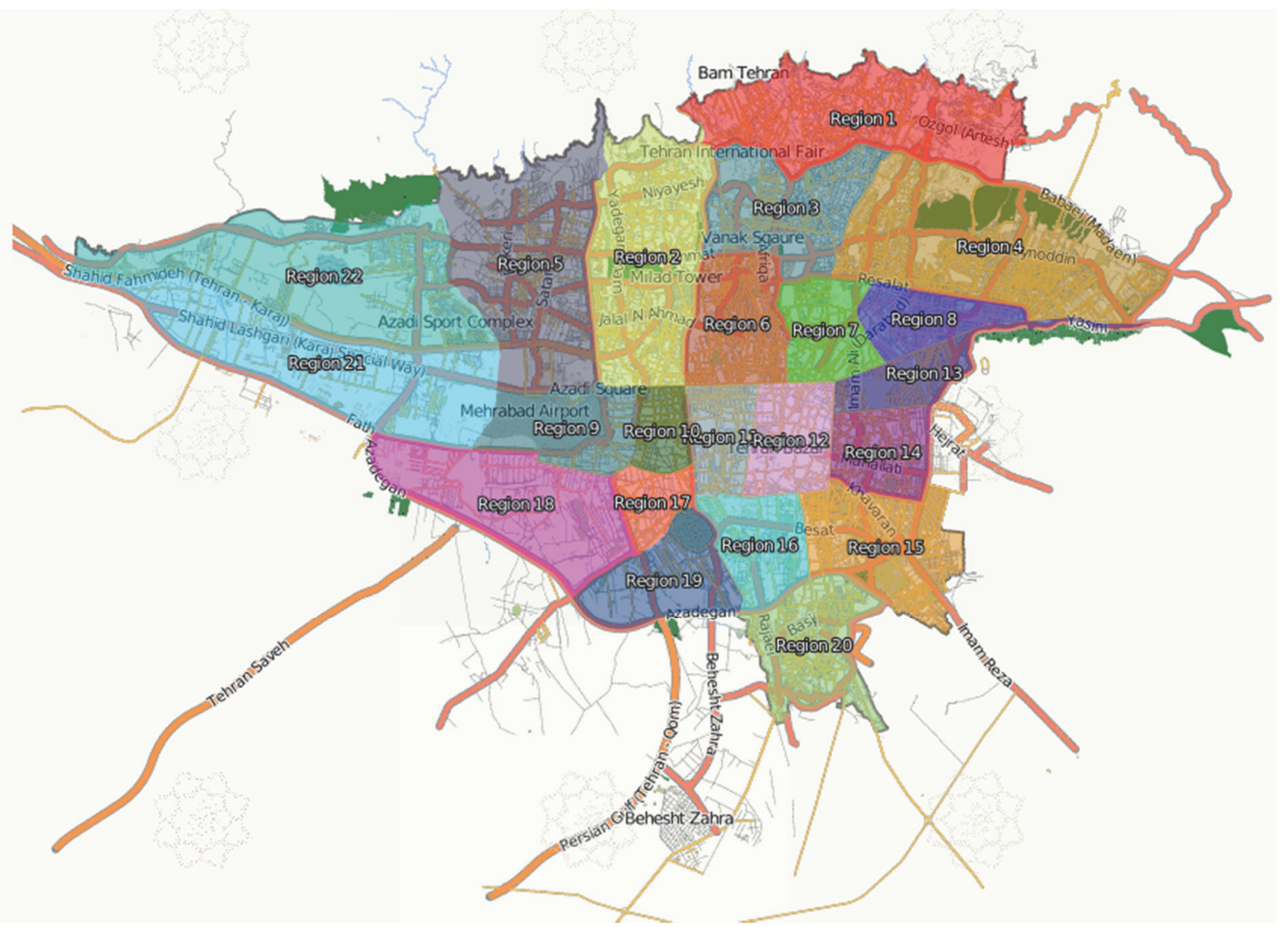

Fig. 5. Twenty-two districts of Tehran

On this basis, the given network was composed of 1 logistic center (central market) with indefinite capacity, 22 candidate places for constructing urban distribution centers, and 171 sales terminals as demand points. Moreover, since the demand for all fruit was supplied by the bulk-sales markets in a unit of weight (e.g. in ton), the number of commodities was considered equal to 1 . The constraint of the available budget for constructing the distribution centers has not been taken into account. A total of 5 distribution centers would be constructed, 3 of which would be equipped with low-carbon equipment.

To estimate the parameters related to the sales markets' demand with regard to the statistics published by Tehran Municipality in 2015, which is retrievable on the website of this organization, the population of the 22 districts was considered as the basis for estimation. Thus, the sales markets would have different demands depending on the district wherein they were located. Basically, the more the population of a district, the higher the upper and lower limits of demand for that district would be. The demand occurrence rate for the districts with very low populations was considered less than that of the districts with high population. Table 1 represents the values of these parameters. 
Table 1

Demand parameters

\begin{tabular}{cccccc}
\hline $\begin{array}{l}\text { Districts of Tehran } \\
\text { sorted in the order of highest-to- } \\
\text { lowest population }\end{array}$ & $\begin{array}{l}\text { Population } \\
\text { (individuals) }\end{array}$ & $\begin{array}{l}\text { Number } \\
\text { of markets }\end{array}$ & $\begin{array}{l}\text { Lower limit } \\
\text { of demand }\end{array}$ & $\begin{array}{l}\text { Upper limit of } \\
\text { demand }\end{array}$ & $\begin{array}{l}\text { Demand } \\
\text { occurrence rate }\end{array}$ \\
\hline 5 & 865467 & 15 & 8 & 26 & 1.5 \\
2 & 848433 & 10 & 8 & 25 & 1.5 \\
15 & 633905 & 2 & 7 & 24 & 1.6 \\
1 & 621197 & 17 & 7 & 23 & 1.6 \\
18 & 462323 & 13 & 6 & 21 & 1.8 \\
14 & 438919 & 8 & 6 & 20 & 2 \\
\hline 8 & 393640 & 9 & 5 & 19 & 2 \\
20 & 377419 & 5 & 5 & 18 & 2 \\
\hline 3 & 351781 & 6 & 5 & 17 & 2 \\
\hline 1 & 325193 & 7 & 5 & 16 & 2 \\
11 & 309844 & 7 & 5 & 15 & 1.7 \\
13 & 296179 & 6 & 4 & 14 & 1.7 \\
16 & 293734 & 4 & 4 & 13 & 1.7 \\
17 & 287943 & 8 & 4 & 12 & 1.7 \\
\hline 12 & 272113 & 8 & 4 & 11 & 1.5 \\
\hline 6 & 248816 & 7 & 3 & 10 & 1.5 \\
\hline 21 & 234370 & 9 & 3 & 9 & 1.5 \\
\hline
\end{tabular}

Due to the unavailability of further information, other parameters of the model were initiated in accordance with the following explanations.

Fixed costs to establish distribution centers are evenly between 5,000 and 6,000 and cost of the processing variable in the distribution centers uniformly ranged between 10 and 20 monetary units. The carbon emission reduction percentage at any distribution center, where the low-carbon resources were considered, was equal to $50 \%$. Also, the carbon tax rate was assumed equal to $30 \%$. The serviceproviding rate at the first to third levels of the network was assumed equal to 12,8 , and 4 , respectively. The average speed of the vehicles at the first and second levels of the network was equal to 30 and 20 $\mathrm{km} / \mathrm{h}$, respectively. Naturally, the transportation time between the network levels was equal to the distances of the network points divided by the mean speed. Other parameters are initialized in Table 2 :

Table 2

Values of other parameters

\begin{tabular}{cl}
\hline$v_{j}^{r}$ & Uniformly ranging between 10 and 20 monetary units per unit of commodity \\
$t_{j}^{r}$ & Uniformly ranging between 4 and 5 monetary units per unit of commodity and unit of distance \\
$s_{i}^{r}$ & Uniformly ranging between 2 and 4 monetary units per unit of commodity and unit of distance \\
$p e_{j}$ & Uniformly ranging between 100 and 600 units of carbon emission per unit of commodity \\
$t e_{j}$ & $\begin{array}{l}\text { Uniformly ranging between } 0.5 \text { and } 3 \text { units of carbon emission per unit of commodity and } \\
\text { unit of distance }\end{array}$ \\
$e_{i}$ & $\begin{array}{l}\text { Uniformly ranging between } 1 \text { and } 2 \text { units of carbon emission per unit of commodity and unit } \\
\text { of distance }\end{array}$ \\
$U_{i}$ & Uniformly ranging between 1000 and 2000 units of commodity \\
\hline
\end{tabular}




\subsection{Solution and results}

Considering the above values, now, we describe the results obtained from solving the model via epsilon constraint method and by BARON solver in GAMS software. Epsilon constraint method is based on converting a multi-objective optimization problem into a single-objective optimization problem. This method is one of the most well-known approaches for dealing with the multi-objective optimization problems, which solves such problems by transferring all the objective functions, except one, to the constraints at each stage. In fact, in this method, one of the objectives of the given problem is optimized as the main objective relative to the other objectives as constraints, which is called epsilon constraint (Ehrgott, 2005; Bérubé et al., 2009). This method was first developed by Haimes et al. (1971) and, then, its details were described in Changkong and Haimes (1983) study.

In the proposed problem in the present study, the first objective, i.e. the total operational cost, was investigated as the main objective and the second objective, i.e. the response time, as the secondary objective. Therefore, regarding the epsilon constraint method, formulation of the objectives was as follows:

$\operatorname{Min}$ TC

$R T \leq \varepsilon$

In order to determine the Pareto points, first, each objective function was solved separately. The obtained results are reported in Table 3.

Table 3

Results of solving the model by each of the objective functions separately

\begin{tabular}{lcccccc}
\hline Objective Type & TC & RT (hr) & $\mathrm{Z}_{\mathrm{j}}$ & $\mathrm{P}_{\mathrm{j}}$ & $\mathrm{WT}_{\mathrm{q}}$ & $\mathrm{LR}_{\mathrm{q}}$ \\
\hline Min TC & 5997060.690 & 17.180 & $6,9,15,17,18$ & $9,15,17$ & 2.490 & 0.967 \\
Min RT & 6347208.016 & 14.126 & $5,7,16,17,19$ & $16,17,19$ & 2.492 & 0.950 \\
\hline
\end{tabular}

The ideal value for the first objective function and the worst value for the second one were 5997060 and 17.180, respectively, and the problem did not have any multiple optimal solutions. Thus, there was no solution that could dominate the above optimal solution. Subsequently, based on the $\varepsilon$-constraint method and considering $\Delta=0.3$, the optimal points of the problem were generated, followed then by presenting the best obtained solutions, meaning the non-dominated Pareto solutions for the objective functions. The consecutive repetitions of the $\varepsilon$-constraint method yielded 8 solutions for the problem, the characteristics of which are provided in Table 4. The values of the objective functions provided in the first and the last rows of this table represent the ideal and nadir values for the two objective functions.

Table 4

Results of solving the model for different values of epsilon

\begin{tabular}{ccccc}
\hline Number & epsilon (E) & Objective 1 (TC) & Objective 2 (RT) & $Z_{j}$ \\
\hline 1 & - & 5997060.690 & 17.180 & $6,9,15,17,18$ \\
2 & 16.88 & 6087870.074 & 16.878 & $6,9,15,17,18$ \\
3 & 16.58 & 6157347.378 & 16.570 & $6,9,15,17,19$ \\
4 & 16.28 & 6290313.002 & 16.273 & $7,9,15,17,18$ \\
5 & 15.98 & 6416012.485 & 15.978 & $1,5,11,12,19$ \\
6 & 15.68 & 6163586.238 & 15.643 & $3,9,15,17,18$ \\
7 & 15.38 & 6256793.929 & 15.233 & $7,16,17,19,20$ \\
8 & - & 6347208.016 & 14.126 & $5,7,16,17,19$ \\
\hline
\end{tabular}


It should be noted that some of these points were dominated by others and, thus, eliminated from among the Pareto and effective solutions. Fig. 6 shows all Pareto and effective points after eliminating the dominated points. Thus, the number of Pareto solutions obtained for this problem with $\Delta=0.3$ was 6 .

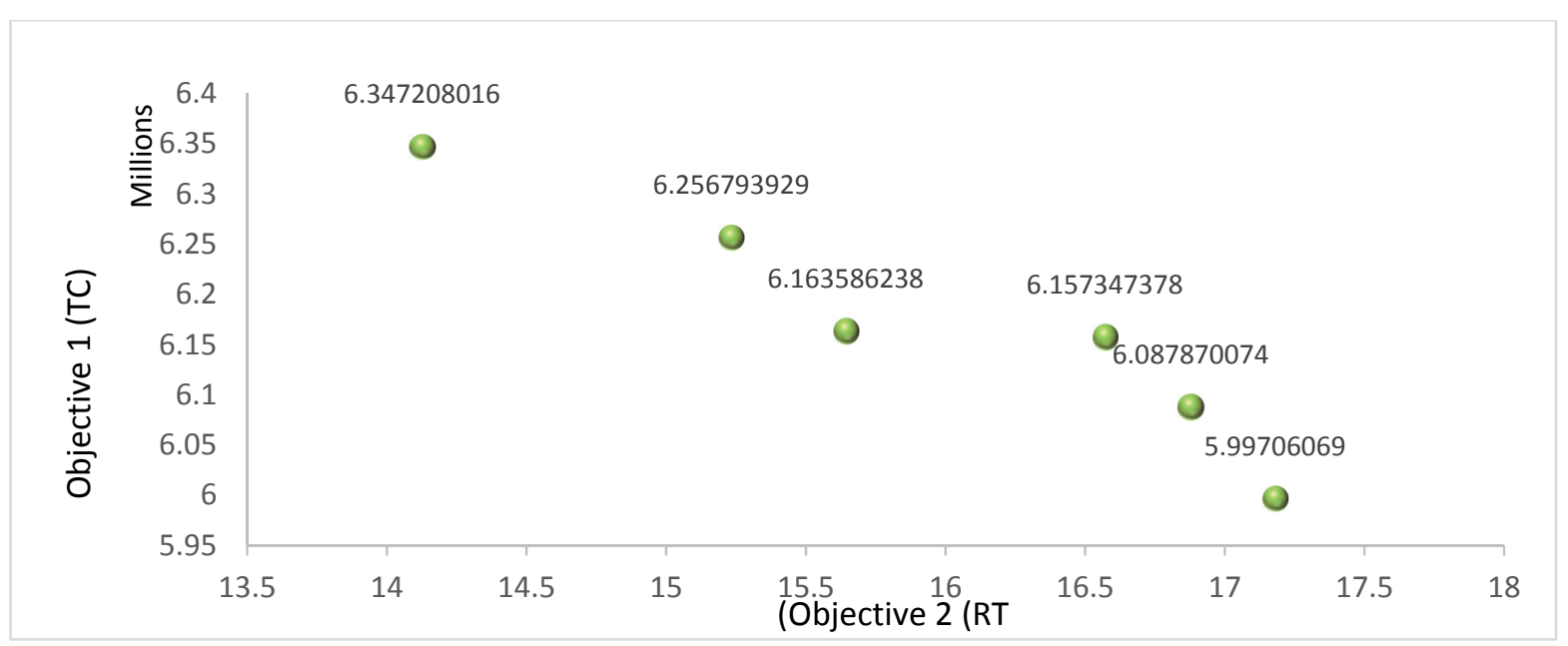

Fig. 6. Dominated and non-dominated points

In most of the obtained Pareto solutions, District (19) and its adjacent districts were activated as distribution centers. Since the logistic center, i.e. the central market of fruit and vegetable, was located in District (19), it could simultaneously play the role of a distribution center as well and cover the demand of District (19) and its adjacent districts. Hence, considering the approach that there was no need for a distribution center in the districts in the southern part of Tehran, the focus should be put on the location of the other 4 distribution centers in the remaining districts. Therefore, the demands of Districts (15), (16), (17), (18), (19), and (20) could be met by the Fruit and Vegetable Central Market. The other 4 distribution centers in the remaining districts, which included 16 districts, would be located. Results of solving the model through this approach, which was more appropriate than the previous state, are provided in Table 5.

Table 5

Results of solving the model using each of the objective function separately via the new approach

\begin{tabular}{ccccccc}
\hline Objective Type & TC & RT (hr) & $Z_{\mathrm{j}}$ & $\mathrm{P}_{\mathrm{j}}$ & $\mathrm{WT}_{\mathrm{q}}$ & $\mathrm{LR}_{\mathrm{q}}$ \\
\hline Min TC & 4760693.806 & 15.240 & $1,6,9,21$ & $6,9,21$ & 1.460 & 0.370 \\
Min RT & 4990437.374 & 10.750 & $5,7,10,12$ & $5,10,12$ & 1.464 & 0.342 \\
\hline
\end{tabular}

In this state, the ideal value for the first objective function and the worst value for the second one were equal to 4760693 and 15.25 , respectively. Subsequently, based on the $\varepsilon$-constraint method and considering $\Delta=0.5$, the optimal points of the problem were generated, followed then by presenting the best obtained solutions, i.e. the non-dominated Pareto solutions for the objective functions.

Table 6

Results of solving the model for different values of epsilon via the new approach

\begin{tabular}{ccccc}
\hline Number & epsilon $(\boldsymbol{\varepsilon})$ & Objective 1 (TC) & Objective 2 (RT) & $Z_{i}$ \\
\hline 1 & - & 4760693.806 & 15.240 & $1,6,9,21$ \\
2 & 14.74 & 4762170.056 & 14.658 & $6,7,9,21$ \\
3 & 14.24 & 4765207.470 & 14.168 & $6,7,9,21$ \\
4 & 13.74 & 4769470.332 & 13.643 & $6,7,9,21$ \\
5 & 13.24 & 4774202.909 & 13.165 & $1,6,9,21$ \\
6 & 12.74 & 4780322.828 & 12.705 & $1,6,9,21$ \\
7 & 12.24 & 4794240.301 & 12.170 & $1,6,9,21$ \\
8 & 11.74 & 4814024.011 & 11.733 & $1,6,7,9$ \\
9 & 11.24 & 4857105.904 & 11.235 & $1,7,9,12$ \\
10 & - & 4990437.374 & 10.750 & $5,7,10,12$ \\
\hline
\end{tabular}


The consecutive repetitions of the $\varepsilon$-constraint method yielded 10 solutions for the problem, the characteristics of which are provided in Table 6 . The values of the objective functions provided in the first and last rows of this table represent the ideal and nadir values for the two objective functions. Fig. 7 shows all the effective points. Therefore, the number of Pareto solutions obtained for this problems via the above-mentioned approach with $\Delta=0.5$ was equal to 10 . Selecting one of the effective points for execution was based on the priorities of the decision-makers and beneficiaries.

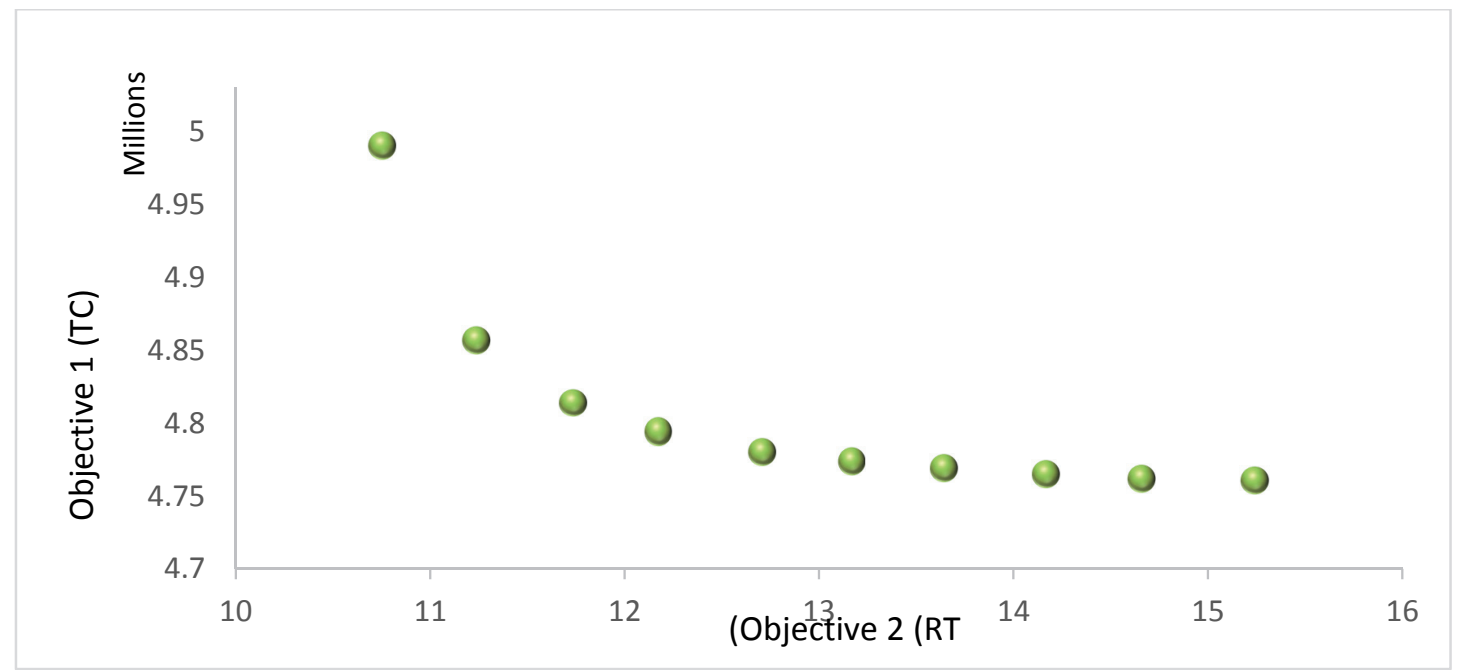

Fig. 7. Pareto points obtained via the new approach

One of the effective points for execution was selected based on the priorities of the decision-makers and beneficiaries. The important point about the set of effective points obtained from the $\varepsilon$-constraint method was its precision and perfectness. In other words, in case of using other methods of solving the multi-objective problems for the mathematical model, the final solution obtained from these methods would be one of the effective solutions obtained via the $\varepsilon$-constraint method.

\section{Augmented \&-constraint method}

Since Miettinen (1999) has found that the solutions obtained by $\varepsilon$-constraint method is a weak Pareto optimal solutions for multi-objective optimization, an improved method, namely, augmented $\varepsilon$ constraint method is applied in order to generate better Pareto solutions. According to the Mavrotas (2009), by applying some modifications to the method, the results can be improved. These modifications in the problem with $p$ objective functions are described as follows,

$$
\begin{array}{ll}
\min & f_{r}(x)+\operatorname{eps}\left(\sum_{\substack{t=1, t \neq r}}^{p} s_{t}\right) \\
\text { s.t. } & X \in S \\
& f_{t}(x)+s_{t}=\varepsilon_{t} \quad \text { for all } t \neq r
\end{array}
$$

where $s_{t}$ is the slack variables considered for the problem and eps is a small value between 10-3 and 10-6 based on Mavrotas (2009). Accordingly, the solutions obtained by augmented $\varepsilon$-constraint method are the only efficient solutions and the weakly efficient solutions generation is avoided (Mavrotas, 2009).

In order to present a comparison between $\varepsilon$-constraint method and augmented $\varepsilon$-constraint method, the augmented $\varepsilon$-constraint is applied by considering 10 breakpoints and $\Delta=0.5$, and the obtained results are shown in Table 7. As it is clear in Table 7, the obtained results by the augmented approach are better in terms of both objective functions. In other words, it makes all the Pareto solutions obtained by traditional $\varepsilon$-constraint method dominated. The solutions have differences in $\mathrm{Z}_{\mathrm{j}}$ values in some breakpoints too. Fig. 8 illustrates the obtained Pareto front by the augmented approach. As it is obvious, 
it has made a different front compared to the traditional one which is depicted in Fig. 9 to show this difference. Therefore, the solutions obtained by the augmented approach proposed as optimal solutions.

Table 7

Results of solving the model for different values of epsilon via augmented approach

\begin{tabular}{ccccc}
\hline Number & epsilon $(\boldsymbol{\varepsilon})$ & Objective 1 (TC) & Objective 2 (RT) & $Z_{j}$ \\
\hline 1 & - & 4748778.14 & 14.52 & $5,6,9,21$ \\
2 & 14.42 & 4749883.77 & 14.34 & $1,6,9,21$ \\
3 & 14.02 & 4750909.08 & 13.95 & $1,6,9,21$ \\
4 & 13.32 & 4755028.78 & 13.23 & $1,6,9,21$ \\
5 & 12.99 & 4760172.03 & 12.92 & $1,6,9,21$ \\
6 & 12.33 & 4765096.73 & 12.3 & $6,7,9,21$ \\
7 & 11.74 & 4774480.36 & 11.67 & $6,7,9,21$ \\
8 & 11.29 & 4795771.16 & 11.29 & $1,6,7,9$ \\
9 & 10.87 & 4828147.06 & 10.84 & $1,7,9,12$ \\
10 & - & 4983968.69 & 10.61 & $5,7,10,12$ \\
\hline
\end{tabular}

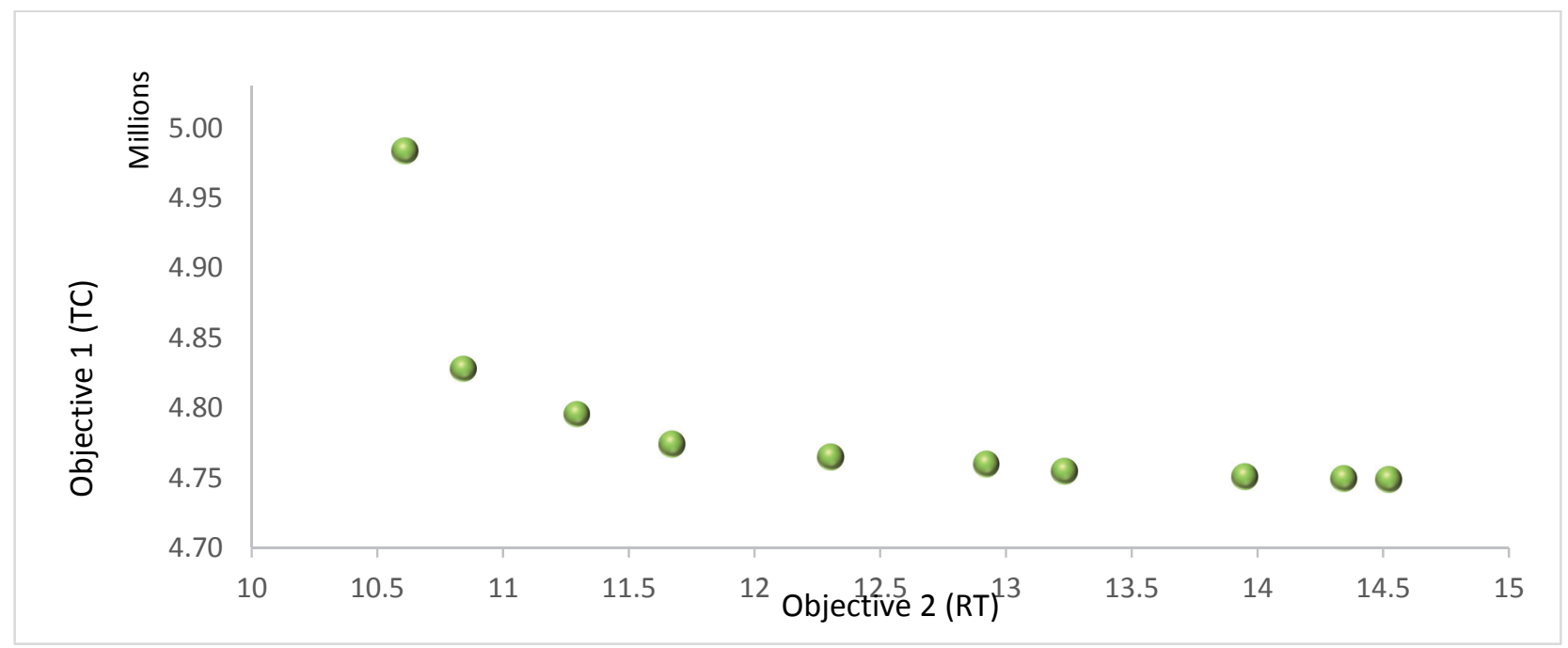

Fig. 8. Pareto points obtained via the augmented approach

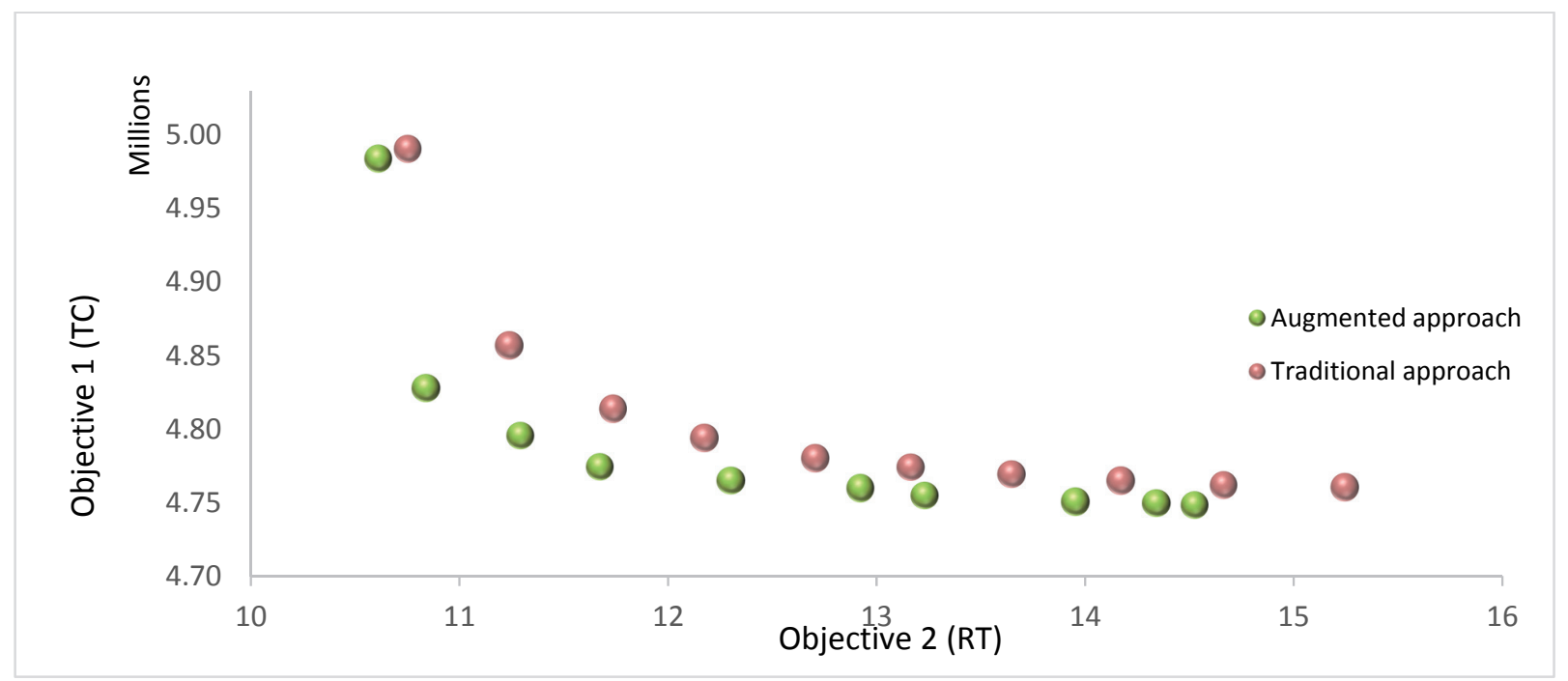

Fig. 9. Comparison between Pareto points obtained via the augmented and traditional approaches 


\section{Conclusion}

It is crucially necessary to attempt to reduce the costs and pollutants within the city transportation and logistics distribution network, especially in metropolitan areas with dense population. Meanwhile, apropos of the necessary and perishable commodities, it is essential to rapidly meet the demands to the possible extent. In the present paper, a bi-objective mathematical model was proposed for deigning the city logistics distribution network based on the queuing theory. In this model, the first objective was to minimize the environmental and economic costs at the network level and the second one was to minimize the response time in the network. The major innovations of this study were the application of the queuing theory in order to improve precision, flexibility, and applicability of the modellings of city logistics, on one hand, and application of the carbon tax policy as well as the incentive policy of allocation of low-carbon resources to distribution centers in order to reduce the pollutants emission rate on the other hand. Subsequently, as a case study with practical use, the fruit distribution network in Tehran was investigated and redesigned. On the whole, findings of the present study by $\varepsilon$-constraint methods have indicated the good performance of the proposed model in redesigning the given network. Integrating the problem presented in this study with the vehicle routing problems, assuming the distances between the intra-city centers as orthogonal, and applying better methods for problem solving are some of the suggestions that can be presented for future studies.

\section{References}

Anand, N., Quak, H., van Duin, R., \& Tavasszy, L. (2012). City logistics modeling efforts: Trends and gaps-A review. Procedia-Social and Behavioral Sciences, 39, 101-115.

Anand, N., Van Duin, R., Quak, H., \& Tavasszy, L. (2015). Relevance of city logistics modelling efforts: a review. Transport Reviews, 35(6), 701-719.

Bérubé, J. F., Gendreau, M., \& Potvin, J. Y. (2009). An exact $\epsilon$-constraint method for bi-objective combinatorial optimization problems: Application to the Traveling Salesman Problem with Profits. European Journal of Operational Research, 194(1), 39-50.

Changkong, V., \& Haimes, Y. Y. (1983). Multiobjective decision making: Theory and methodology. In North-Holland Series in System Science and Engineering (Vol. 8). Elsevier Science Publishing Co New York NY.

Crainic, T. G., Ricciardi, N., \& Storchi, G. (2009). Models for evaluating and planning city logistics systems. Transportation science, 43(4), 432-454.

Dablanc, L. (2007). Goods transport in large European cities: Difficult to organize, difficult to modernize. Transportation Research Part A: Policy and Practice, 41(3), 280-285.

Duren, R. M., \& Miller, C. E. (2012). Measuring the carbon emissions of megacities. Nature Climate Change, 2(8), 560.

Ehrgott, M. (2005). Multicriteria optimization (Vol. 491). Springer Science \& Business Media.

Haimes, Y. Y. (1971). On a bicriterion formulation of the problems of integrated system identification and system optimization. IEEE Transactions on Systems, Man, and Cybernetics, 1(3), 296-297.

He, X., Hu, W., Wu, J. H., \& Wang, C. (2013). Improving emergency goods transportation performance in metropolitan areas under multi-echelon queuing conditions. Procedia-Social and Behavioral Sciences, 96, 2466-2479.

Barceló, J., Grzybowska, H., \& Pardo, S. (2005). Combining vehicle routing models and microscopic traffic simulation to model and evaluating city logistics applications. In The proceedings of the 16th mini-EURO conference and 10th meeting of EWGT, Italy.

Mavrotas, G. (2009). Effective implementation of the $\varepsilon$-constraint method in multi-objective mathematical programming problems. Applied Mathematics and Computation, 213(2), 455-465.

Miettinen, K. (1999). Nonlinear Multiobjective Optimization. volume 12 of International Series in Operations Research and Management Science.

Moutaoukil, A., Neubert, G., \& Derrouiche, R. (2015). Urban Freight Distribution: The impact of delivery time on sustainability. IFAC-PapersOnLine, 48(3), 2368-2373.

Muñuzuri, J., \& Cortés, P. (2012). Recent advances and future trends in city logistics. 
Saeedi, F., Teimoury, E., \& Makui, A. (2018). Designing sustainable city logistics distribution network using a probabilistic bi-objective mathematical model. Uncertain Supply Chain Management, 6(4), 357-374.

Taniguchi, E. (2001). City logistics: Network modelling and intelligent transport systems. Amsterdam: Pergamon.

Taniguchi, E., \& Thompson, R. G. (Eds.). (2014). City logistics: Mapping the future. CRC Press.

Taniguchi, E., Thompson, R. G., \& Yamada, T. (2014). Recent trends and innovations in modelling city logistics. Procedia-Social and Behavioral Sciences, 125, 4-14.

Teimoury, E., Saeedi, F., \& Makui, A. (2017). A Mathematical Model for City Logistics Distribution Network Design with the Aim of Minimizing Response Time. International Journal of Industrial Engineering \& Production Research, 28(1), 21-31.

Qiu, F.Y., \& Yang, D. (2005). City Logistics in China: An Overview. In Recent Advances in City Logistics (E. Taniguchi and R. G. Thompson, eds.). Elsevier, New York, p. 417-427.

Wolpert, S., \& Reuter, C. (2012). Status quo of city logistics in scientific literature: systematic review. Transportation Research Record: Journal of the Transportation Research Board, 2269, 110-116.

Yang, J., Guo, J., \& Ma, S. (2016). Low-carbon city logistics distribution network design with resource deployment. Journal of Cleaner Production, 119, 223-228.

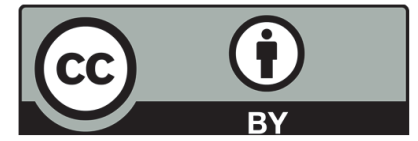

(C) 2019 by the authors; licensee Growing Science, Canada. This is an open access article distributed under the terms and conditions of the Creative Commons Attribution (CC-BY) license (http://creativecommons.org/licenses/by/4.0/). 